\title{
INDICADORES SÓCIO-DEMOGRÁFICOS DE CRIANÇAS DE 0-6 ANOS NO BRASIL*
}

Fúlvia Rosemberg ${ }^{1}$

\section{INTRODUÇÃO}

Qualquer reflexão sobre a infancia brasileira, seja sobre seu desenvolvimento biopsicossocial, seja sobre propostas para melhoria de sua condição de vida, deveria partir da análise de indicadores sócio-demográficos que reflitam, para esta faixa da população, as determinações macro-estruturais de sua inserção social.

Houve um tempo que segmentos da cultura académica brasileira rejeitavam indicadores sócio-demográficos, seja pela desconfiança quanto a sua fidelidade, seja pelo modismo que vingava e que atribuia os epítetos de "racionaria" ou "positivista" à informação quantitativa. Com a melhoria progressiva das pesquisas realizadas por vários 6rgãos estaduais e federais (como as realizadas pela Fundação SEADE e pelo IBGE) e o uso estratégico e político de informações estatísticas, felizmente este preconceito anti-quantitativo foi se desfazendo, possibilitando a coleta e o processan.e. $\wedge$ l o de dados cada vez mais ricos.

Sobre a pequena infancia necessitamos, ainda, de estatísticas melhores e mais diversificadas. Por exemplo, a despeito do grande aporte da série Perfil Estatfstico de Mães e Criancas no Brasil (publicada através de convencia IBGE/UNICEF), lacunas importantes permanecem, como a ausência quase total de dados desagregados por raça e a fragilidade de estatísticas sobre educação pré-escolar.

Este artigo tem por meta sistematizar algumas das informações disponíveis sobre crianças de $\mathrm{O}$ a 6 anos e que, a nosso ver, são indispensáveis ao trabalho teórico e prático de profissionais que lidam com esta faixa etária.

\section{COM MENOS DE SETE ANOS}

Vivem hoje no Brasil aproximadamente 24 milhões de crianças com menos de sete anos, correspondendo a cerca de $17 \%$ da população brasileira. As crianças nesta faixa etária se concentram predominantemente nas regiões sudeste e nordeste que, conjuntamente, abrigam $75 \%$ dos brasileiros com menos de sete anos ${ }^{2}$.

A participação do grupo de 0 a 6 anos na composição populacional das diferentes regiões apresenta variações: as regiões sudeste e sul situam-se abaixo da média nacional (16\%) e as demais, acima - região norte (20\%), nordeste (21\%) e centro-oeste (18\%) - evidenciando padrões diversos de fecundidade.

Sua concentração é mais intensa em zona urbana (69\%) que em rural, porém é necessário que se destaquem as variações regionais: a região sudeste apresenta a taxa máxima de concentração urbana (82\% das crianças de 0 a 6 anos do sudeste vivem em zona urbana) e a região nordeste, a concentração máxima de população infantil em zona rural (50\%). Há que se destacar, também, que nas dez regiões metropolitanas vivem cerca de $13 \%$ das crianças brasileiras com menos de 7 anos.

Dentro do grupo de $\mathrm{O}$ a 6 anos, a distribuição por subgrupos etários é bastante uniforme: $14 \%$ têm até um ano de idade; $42 \%$ de 1 a 3 anos e $44 \%$ de 4 a 6 anos.

Vale destacar a posição especial ocupada pela região nordeste: constitui, dentre as regiões brasileiras, aquela em que o segmento de $\mathrm{O}$ a 6 anos contribui com a maior proporção na constituição da população regional; o grupo etário de $\mathrm{O}$ a 1 ano (o mais vulnerável) é, proporcionalmente,

\footnotetext{
* Texto realizado no contexto do Serviço de Documentação sobre Creches que conta com o apoio da Fundação Ford (dotação 855/ 0937).

1 Professora associada da pós-graduação da Psicologia Social da Pontiffcia Universidade Católica-SP e pesquisadora da Fundação Carlos Chagas.

2 Quando não forem citadas fontes especificas os dados aqui referidos provem da PNAD 86.
} 
mais frequente nesta região que nas demais $(1,1$ milhão de crianças da região nordeste têm até um ano de idade); apresenta a maior concentração nacional de crianças residindo em zona rural (55\% das crianças brasileiras de $\mathrm{O}$ a 6 anos que vivem em zona rural provem da região nordeste).

Estudos recentes vêm apontando que as crianças brasileiras tendem a provir, em maior intensidade que adultos, de famílias com baixos rendimentos. Esta observação pode ser explicada por um conjunto de fatores: ciclo de vida da família; taxa de fecundidade diferenciado nos diferentes estratos económicos; ausência de filhos maiores que possam contribuir para o aumento do orçamento doméstico; impossibilidade de as mães trabalharem fora quando seus filhos são pequenas por falta de equipamentos alternativos.

Dados recentes (1986) apontam que 43\% das crianças de 0 a 6 anos vivem em domicílios particulares cuja renda per capita mensal era de até meio salário mínimo, o que, de acordo com a classificação adorada, permitiria caracterizá-las como vivendo em "situação de carência". Dentre estas, cerca de $20 \%$ vivem em domicílios particulares cuja renda familiar per capita é de até um quarto de salário mfnimo, portanto, de acordo com a classificação em uso, estariam em situação de "pobreza absoluta". Há que se destacar que, por se ter acesso somente a dados referentes a crianças vivendo em domicílios particulares, tais cifras omitem um número desconhecido de crianças institucionalizadas (em internatos e orfanatos), que são provavelmente provenientes de famílias com os mais baixos rendimentos.

Como os demais indicadores sóciodemográficos, são as crianças provenientes de zona rural e da região nordeste as que em maior número vivem em famílias pobres: $40 \%$ das crianças de $\mathrm{O}$ a 6 anos, residentes no nordeste, vivem em condições de pobreza absoluta, sendo que esta porcentagem ultrapassa o nível de 50\% quando se consideram apenas as crianças provenientes da zona rural desta região.

É necessário, também, que se destaque o número bastante elevado de crianças entre O e 6 anos das regiões metropolitanas situadas na faixa de pobreza absoluta: são 733.308 crianças, ou seja, $24 \%$ do total das que vivem nestas regiões. Diagnósticos realizados recentemente (Campos et al., 1988; Fundação Carlos Chagas, 1989; Rosemberg, 1989) vêm reafirmando a necessidade de cuidados especiais para as crianças residindo nestas áreas, levando-se em conta os movimentos migratórios e o processo de pauperização das famílias mais pobres que são exatamente aquelas que contam com maior número de crianças pequenas. O efeito perverso observado nas regiões metro- politanas consiste na expulsão de fanulias pobres, com crianças pequenas, para áreas que dispõem de infra-estrutura urbana de pior qualidade (saúde. saneamento, educação), com pequeno poder de pressão junto ao poder público e baixo nível de organização comunitária.

A análise da participação das mulheres no mercado de trabalho permite que se apreenda a intrincada associação entre pobreza familiar, incidência de crianças pequenas e trabalho materno. No Brasil, como em outros países, idade, posição na família, estado conjugal, maternidade e nível de escolaridade são variaveis que afetam a participação das mulheres no mercado de trabalho. As mulheres que mais intensamente participam do mercado de trabalho são: as que se situam na faixa etária entre 18 e 24 anos; as separadas (que arcam, em geral, com a chefia de suas famílias), seguidas das solteiras; as que atingiram nível mais elevado de instrução (Bruschini, 1989). A presença de filhos interfere de forma marcante na participação feminina na PEA (População Economicamente Ativa): a atividade das mulheres declina quando se tornam mães, declínio que se acentua sensivelmente quando têm mais de um filho.

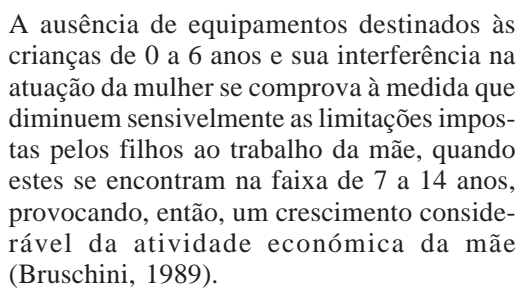
crianças de 0 a 6 anos e sua interferência na atuação da mulher se comprova à medida que diminuem sensivelmente as limitações impostas pelos filhos ao trabalho da mãe, quando estes se encontram na faixa de 7 a 14 anos, provocando, então, um crescimento considerável da atividade económica da mãe (Bruschini, 1989).

A autora considera que as mais elevadas taxas de participação feminina na PEA associadas à escolaridade podem ser compreendidas pelo falo de que "estas mulheres apresentam um menor número de filhos, o que facilitaria sua saída, e, ainda, dispõem de condições mais favoráveis para arcar com as despesas de estruturas de apoio (empregadas domésticas, escolas maternais, etc.)".

O efeito perverso apontado - a pobreza familiar de mães tendo crianças pequenas impede-as de participarem do mercado de trabalho se evidencia quando se apreende que a proporção de cônjuges (quase exclusivamente mulheres) que trabalhavam fora em 1986 era duas vezes maior (45.\%) nas famílias com rendimento per capita mensal de dois salários mínimos do que naquelas situadas na faixa de pobreza absoluta (apenas 22\% dos cônjuges nas famílias com rendimento per capita mensal de até um quarto de salário mínimo trabalhavam fora).

As condições de saneamento básico dos domicílios em que vivem as crianças pequenas 
constituem indicador valioso quanto ao nível de qualidade de vida de que usufruem, sendo um dos fé fores importantes na determinação de seu estado de saúde. Se, no plano da atividade doméstica, dispor ou não de água corrente en casa pode aumentar ou não o dispêndio de energia para a manual tenção de crianças e adolescentes, para as crianças de até um anã de idade as repercussões se acumulam: a água não tratada e nãc disponível tem implicações mais intensas em crianças biologicamente mais vulneráveis e canaliza a atenção da mãe que poderia ser orientada para o cuidado da criança. Porém, mais uma vez, c que se percebe é a associação de condições de vida desfavoráveis: as crianças menores, mais pobres, provenientes de meio rural e da região nordeste são aquelas que vivem, em maior número, em domicílios considerados inadequados quanto às condições de saneamento básico. Assim, em 1986, viviam em domicílios considerados inadequados no plano do saneamento básico: $60 \%$ das crianças com menos de um ano de idade; 92\% das crianças com menos de um ano de idade provenientes de fantasias cujo rendimento mensal per capita era inferior a um quarto de salário mínimo; 85\% das crianças com menos de um ano de idade que viviam na região nordeste; $96 \%$ das crianças com menos de um ano de idade que viviam em zona rural. Obviamente, estes fatores têm um efeito cumulativo, o que acarreta a cifra de $99 \%$ de crianças com menos de um ano de idade, provenientes de famílias rurais com rendimento per capita de até um quarto de salário mínimo e que viviam em domicílios considerados inadequados quanto às condições de saneamento básico.

É necessário assinalar que as condições precárias de saneamento básico nos domicílios em que vivem os bebes devem ser consideradas nas políticas de atendimento à pequena infancia: programas, projetos ou modalidades de atendimento previstos não poderiam, no plano do saneamento, reproduzir as condições de moradia destas crianças. Mesmo que os planos de saneamento prevejam - a médio, curto ou longo prazo - uma melhoria geral dos domicílios particulares, creches e pré-escolas a serem projetadas no Brasil para uma implantação imediata deveriam prever cuidadosamente uma infra-estrutura de saneamento adequada, pois se sabe que o convívio em coletividade para crianças pequenas pode se tornar um foco irradiador e multiplicador de contágio. Alguns programas implantados no Brasil foram particularmente atenciosos quanto a este aspecto. Por exemplo, as creches instaladas pela Prefeitura de Itu (estado de São Paulo) dispõem, além de esgoto e água corrente, de um sistema de filtragem geral da água utilizada no prédio o que permite, sem dúvida nenhuma, maior autonomia para crianças (e funcionárias também) com o menor risco possível de contágio. Outros, ao contrário, quando se utilizam de equipamentos "ociosos" da comunidade, tendem a reproduzir as condições de saneamento básico dos domicílios das crianças pobres.

Diante deste quadro de pobreza que caracteriza a pequena infancia brasileira não há que se espantar com os altos coeficientes de mortalidade infantil (número de óbitos de menores de um ano por cada mil nascidos vivos) e sua distribuição diferenciado pelo território nacional. Em 1986, o coeficiente de mortalidade infantil brasileiro era de 53,0 por mil, sendo que na região nordeste ultrapassava em muito a média nacional (74,7 por mil), taxa menos catastrófica que aquela observada em 1980, quando o coeficiente brasileiro era de 76,2 por mil e o nordestino de 120 por mil. Porém, o perfil da curva de mortalidade infantil não tem apresentado um descenso contínuo, ocorrendo flutuações decorrentes da crise económica. Com efeito, durante os anos de 1983 e 1984 observou-se uma interrupção na queda do coeficiente (principalmente nas regiões norte e nordeste que voltaram a patamares próximos ou superiores aos de 1980), anos que corresponderam ao período mais agudo da crise económica (Becker, 1988).

As regiões, nas quais o impacto da crise económica sobre o coeficiente de mortalidade infantil foi menor, dispunham de uma boa infra-estrutura de saneamento e serviços de saúde, e de programas de alimentação destinados à população (Becker, 1988). Além disso, é importante destacar que nestas regiões, no período anterior à crise, as crianças mais pobres (portanto mais suscetíveis ao impacto da crise e com menor esperança de vida) eram significativamente menos numerosas, e menos pobres, que nas regiões norte e nordeste. No período anterior à crise, a renda média dos 50,0\% mais pobres do nordeste era $130 \%$ menor que a da populacão equivalente no sudeste (Chahad \& Cervini, 1988).

Documento do Banco Mundial (World Bank, 1988, p. 16) revela que as crianças menores de cinco anos de idade, que constituem 13\% da população, recebem apenas 7\% do total de benefícios sociais distribuídos; as famílias situadas na faixa de pobreza absoluta tendo crianças com menos de cinco anos, que representam 19\% do total da população, recebem apenas 6\% do total dos benefícios sociais (apud Fundação Carlos Chagas, 1989, p. 1).

Esta distorsão das políticas sociais é bastante evidente quando se analisam dados referentes ao atendimento em creches e pré-escolas no 
país. Apesar de raros, esparsos e nem sempre confiáveis (Rosemberg, 1989), nota-se, nos últimos anos, algum esforço no sentido de melhoria dos dados estatísticas relativos creches e pré-escolas. Prova é a inclusão na Pesquisa Nacional por Amostra de Domicílios (PNAD), em 1985, de um suplemento sobre a população com menos de 17 anos, que incluiu seis quesitos específicos para avaliar a frequência a creches e pré-escolas nas regiões metropolitanas brasileiras.

As informações mais significativas desta avaliação foram transcritas na Tabela 1. Nota-se, em primeiro lugar, que apesar de insuficiente o atendimento parece ter crescido bastante nos últimos anos. Apesar de contarmos, para anos anteriores, com estimativas extremamente frágeis, estudos sugeriam que no inicio da década de 80 um pouco menos de $10 \%$ das crianças entre 0 e 6 anos (ou com menos de sete anos) estariam frequentando creches ou pré-escolas (Rosemberg et al., 1985 , p. 50), porcentagem que sobe para $23 \%$ em 1985 , quando se focalizam apenas as regiões metropolitanas. As variações regionais não parecem ser significativas. Porém, são altas as porcentagens de crianças frequentando instituições particulares. Esta cifra deve ser entendida à luz da ambiguidade dos conceitos "público e particular" quando associados a creche ou pré-escola: as creches particulares não remetem à mesma realidade que a escola particular, pois são geralmente financiadas pelo poder público, geridas por instituições privadas e destinadas à população de baixa renda.

É notável a alta porcentagem da rubrica “paga para freqüentar creche/pré-escola” (87\%), indicando que a maioria das instituições, mesmo públicas, cobram alguma coisa das famílias, mesmo que seja através da Associação de Pais e Mestres.

$\mathrm{O}$ fato de a grande maioria das crianças (80\%) frequentar as creches/pré-escolas em período parcial (até quatro horas) não surpreende, considerando-se ser este o serviço mais acessível, tanto na rede pública quanto na particular.

Um dos dados mais interessantes relaciona-se à idade com que a criança começou a frequentar a creche/pré-escola: $67 \%$ iniciaciaram na faixa etária de 3 a 5 anos; quase um quarto das crianças antes dos três anos, o que indica uma sensível mudança nas atitu des familiares quanto ao significado destes equipamentos. Notase, também, que são pouquissimas (4\%) as crianças que começam a frequentar a creche com menos de um ano, falo este compreensível pela pequena disponibilidade de berçarios em empresas (apenas $0,4 \%$ ) e pelo reduzido número de vagas disponíveis para bebês em creches públicas e conveniadas.
Os dados permitem, também, que se tente uma avaliação do usufruto do direito à creche aos filhos de empregadas regulamenlado pela legislação trabalhista: apenas $1 \%$ das crianças que qüentam creches/pré-escolas utilizam berçario no local de trabalho ou conveniado com a empresa.

Quando se analisam as principais razões evocadas para que as crianças não freqüentem creches/pré-escolas encontramos:

Tabela 1 - Distribuiçăo percentual* das respostas a quesitos relativos crianças de 0 a 6 anos, em 10 regióes metropolitanas - 1985 .

\begin{tabular}{|c|c|}
\hline Quesitos & $\%$ \\
\hline $\begin{array}{l}\text { Freqüenta creche ou pré-escola } \\
\text { Tipo de creche/pré-escola }\end{array}$ & 3,2 \\
\hline $\begin{array}{l}\text { Tipo de creche/pré-escola } \\
\text { Particular }\end{array}$ & 56,8 \\
\hline $\begin{array}{l}\text { Particular } \\
\text { Pública }\end{array}$ & 34,2 \\
\hline De empresa & $\begin{array}{r}34,2 \\
0,4\end{array}$ \\
\hline Paga para freqüentar creche/pré-escola & 87,4 \\
\hline \multicolumn{2}{|l|}{$\begin{array}{l}\text { Paga para irequentar crecnéppre-escoid } \\
\text { Jornada }\end{array}$} \\
\hline Ate 4 horas & 80,2 \\
\hline Mais de 4 horas & 9,4 \\
\hline 8 horas ou mais & 6,8 \\
\hline \multicolumn{2}{|l|}{ Idade com que começou a freqüentar } \\
\hline Menos de 1 ano & 4,3 \\
\hline $1-02$ anos & 18,6 \\
\hline $3-5$ anos & 66,7 \\
\hline 6 anos & 6,9 \\
\hline \multicolumn{2}{|l|}{ Por que nåo freqüenta } \\
\hline Não há necessidade & 70,0 \\
\hline Falta de condiçōes financeiras & 15,1 \\
\hline Distante da casa & 5,0 \\
\hline \multicolumn{2}{|l|}{ Com quem fica quando não está na creche/pré-escola } \\
\hline Mãe & 72,4 \\
\hline Irmãos maiores de 13 anos & 1,8 \\
\hline S6́ ou irmão menor de 14 anos & 2,5 \\
\hline $\mathrm{Na}$ rua & 0,0 \\
\hline \multicolumn{2}{|l|}{ Com quem fica a maior parte do tempo } \\
\hline Máe & 78,4 \\
\hline Irmãos maiores de 13 anos & 1,9 \\
\hline S6 ou irmáo menor de 14 anos & 2,7 \\
\hline Na rua & 0,0 \\
\hline
\end{tabular}

ou com auséncia de informaçăo, donde não haver soma de $100 \%$ no quesito.

“nao há necessidade” (70\%), “falta de condições financeiras" (15\%) e "distante de casa” (5\%). Creches e pré-escolas ainda sao consideradas por muitas famílias como alternativa à guarda, quando a mãe trabalha fora, nem sempre evidenciando uma prece cupação educacional. Estes dados devem ser analisados com cautela pois, paralelamente tem-se a informação de frequentes e extensas filas à espera de vagas em equipamentos lotados.

Finalmente, é importante comentar os últimos dados contidos na Tabela 1: quando não estão na creche/pré-escola, as cnanças de $\mathrm{O}$ a 6 anos são cuidadas principalmente pela mãe, sendo muito poucas as que ficam sós, com irmãos ou na rua. E possível que ocoi^ ${ }^{\top}$ Ta censura na resposta a estas perguntas, ajustando-as às expectativas sociais que ainda prevalecem, de que a pessoa mais adequada para cuidar da criança pequena é a mãe. Apesar disto, estas porcentagens constituem as primeiras informações quantitativas disponíveis 
de que o fenómeno Crianças abandonadas” provavelmente não é tão extensivo quanto a média nacional e internacional alardeou nestes últimos anos. Quando assinalamos este falo, não é nossa intenção minimizar as dificuldades de vida das famflias pobres, que constituem a maioria da população brasile . Apenas queremos sinalizar que os argumentos apoiados no 'abandonismo" para extensão da rede de creches e pré-escolas são equivocados, tanto no plano da realidade, quanto da postura políticofilosófica que os orientam, ou da representação que veiculam sobre as formas de organização das famílias pobres. A partir da observação etnográfico, Cláudia Fonseca (1987) tem mostrado o quanto é comum- entre moradores de uma favela no sul do pafs_-crianças serem deixadas por penados às vezes longos com parentes, comadres e conhecidos sem que as mães considerem rompido o vínculo com os filhos.

Esta separação da cnança, que ocorre muitas vezes em mó mantos de crise, quando "as condições mínimas de sobrevivência são colocadas em risco”, ao invés de indicar um abandonismo materno significa, na verdade, que a responsabilidade pelo filho é atribuida pelo grupo quase que exclusivamente à mãe.

Inflacionar o número de crianças abandonadas no país tem sido apontado como Ática manipulatóna, seja para superd nensionar a pobreza a tal nível que ela se transforme em problema insol vel, seja para conseguir ou justificar verbas especiais para populações ditas especiais (no caso, as crianças que hipoteticamente são abandonadas pela família). O que importa é que serviços públicos destinados à população em geral sejam planejados de tal forma que atinjam, sempre e prioritariarnente, os estratos mais pobres, com hábitos de vida por vezes diversos daqueles encontrados na classe média. Se se considera necessário expandir a rede de creches e pré-escolas para todas as famílias que delas queiram se utilizar, esta necessidade é respaldada em direitos recentemente adquiridos por todos os brasileiros e consagrados pela nova Constituição.

Como afirmamos anteriormente são poucas as informações que dispomos sobre crianças de 0 a 6 anos desagregadas por cor, procedimento usado pelo IBGE para avaliar a estrutura racial no país. Apresentamos, na Tabela 2, os principais dados de que dispomos.

Tabela 2 - Indicadores sócio-demográficos por raça entre crianças com menos de 7 anos.

\begin{tabular}{l|r|r|r|c}
\cline { 2 - 4 } & Branca & $\begin{array}{c}\text { Preta } \\
\text { A }\end{array}$ & $\begin{array}{c}\text { Parda } \\
\text { B }\end{array}$ & $\begin{array}{c}\text { Negra } \\
(\mathbf{A}+\mathbf{B})\end{array}$ \\
\hline $\begin{array}{l}\text { Crianças de 0 a 6 anos } \\
\text { Mortalidade infantil (até 1 ano) }\end{array}$ & $54,2 \%$ & - & - & $445,8 \%$ \\
$\begin{array}{l}\text { Freqüentando creche/pré-escola } \\
\quad(0 \text { a 6 anos) }\end{array}$ & $25,3 \%$ & $105,0 \%$ & $102,0 \%$ & $105,0 \%$ \\
$\begin{array}{c}\text { Vivendo em domicílio com } \\
\text { saneamento básico adequado } \\
\text { (até 1 ano) }\end{array}$ & $49,4 \%$ & $34,0 \%$ & $20,3 \%$ & \\
\hline
\end{tabular}

Fontes: 1. Censo 1980, apud LEVINSION (1990).

2. Censo 1980, apud TAMBURO (1987).

3. PNAD 85, apud LEVINSON (1989).

4. PNAD 87, apud ROSEMBERG (1991).

3 Expressão emprestada de Maria Aparecida Ciavatta Franco do seu artigo “Lidando pobremente com a pobreza” (1990). 
Como se observa, os indicadores são sempre piores para os segmentos preto e pardo, o que evidencia tanto uma concentração de pobres nesta população como seu trat unento diferenciado enquanto usuária de equipamentos sociais.

\section{CONSIDERAÇÕES FINAIS}

As políticas sociais, no decorrer da História do Brasil vêm lidando pobremente com a infância pobre ${ }^{3}$. As necessidades específicas desta

\section{REIFRÊNCIAS BIBLIOGRÁFICAS}

BECKER, A. Brasil: principais causas de mortalidade infantil. In: Chahad, J. P. Z. \& Cervini, R. Crise e Infância no Brasil: O impacto das políticas de ajustamento econômico. São Paulo, IPEIUSP/UNICEF, 1988.

BRUSCHINI, C. Tendências da Força de TrabaIho Feminina Brasileira nos Anos Setenta e Oitenta: algumas comparações regionais. São Paulo, Fundação Carlos Chagas, 1989.

CAMPOS, M. M. M. et al. Diagnóstico da Situação da Educação Pré-escolar na Região Metropolitana de São Paulo. São Paulo, Fundação Carlos Chagas, 1988.

CHAHAD, J. P. \& CERVINI, R. (org.). Crise e Infância no Brasil: o impacto das políticas de ajustamento econômico. São Paulo, IPE/USP/ UNICEF, 1988. faixa etária, ou mesmo o respeito aos direitos naturais (como o da vida) são negligenciados, principalmente em períodos de crise e recessão económica. É este o cenário que se vislumbra para o próximo ano. Simultaneamente temos assistido, tristemente, a elaboração e implantação por parte dos últimos governos, de projetos mirabolantes - tivemos o "Bom Menino" - temos agora o Ministério da Criança. Como se pirotecnia substituísse investimento necessário nas arcas fundamentais: saneamento, alimentação, saúde e educação.

FUNDAÇÃO CARLOS CHAGAS (FCC). Aspectos Sócio-educativos e Sugestões para uma Política Nacional de Educação da Criança de O a 6 Anos no Brasil. São Paulo, FCC/IEW UNICEF, 1989.

IBGE. PNAD-1985: Suplemento Situação do Menor. Rio de Janeiro, IBGE, 1986.

ROSEMBERG, F. 0 a 6 anos: desencontro de estatísticas e atendimentos. Cadernos de Pesquisa (71): 3648, nov. 1989.

ROSEMBERG, F. et al. Creches e Pré-escolas. São Paulo, Nobel/Conselho Estadual da Condição Feminina, 1985.

WORLD BANK. Brazil: public spending on social programe; issues and options. Washington, 1988. 